\title{
Desenvolvimento de uma metodologia para as pesquisas de mapeamento de espaços de esporte e lazer de Ponta Grossa, Paraná: um relato de experiência
}

\section{Developing a methodology for research on sports and leisure space mapping in Ponta Grossa, Paraná: an experience report}

\author{
Mariana Ciminelli Maranho \\ Instituto Federal do Paraná - IFPR - Telêmaco Borba - Brasil \\ mariana.maranho@ifpr.edu.br \\ Diego Petyk de Sousa \\ Universidade Estadual de Ponta Grossa - UEPG - Ponta Grossa - Brasil \\ diegopetyk@uol.com.br \\ Edilson de Oliveira \\ Universidade Estadual de Ponta Grossa - UEPG - Ponta Grossa - Brasil \\ edilsonde.oliveira@outlook.com \\ Alfredo Cesar Antunes \\ Universidade Estadual de Ponta Grossa - UEPG - Ponta Grossa - Brasil \\ alfredo.cesar@hotmail.com \\ Miguel Archanjo de Freitas Júnior \\ Universidade Estadual de Ponta Grossa - UEPG - Ponta Grossa - Brasil \\ mfreitasjr@uepg.br \\ Bruno Pedroso \\ Universidade Estadual de Ponta Grossa - UEPG - Ponta Grossa - Brasil \\ prof.brunopedroso@gmail.com \\ Constantino Ribeiro de Oliveira Junior \\ Universidade Estadual de Ponta Grossa - UEPG - Ponta Grossa - Brasil \\ constantinojr47@gmail.com
}

\section{Resumo}

Este estudo buscou descrever o processo de construção de uma metodologia própria para as pesquisas de mapeamento de espaços de práticas de esporte e lazer no município de Ponta Grossa - Paraná. Para tanto, optou-se por uma orientação interdisciplinar para viabilizar diferentes arranjos procedimentais. Dessa forma, o diálogo, especialmente, entre as áreas de educação física e geografia foi fundamental para chegar-se aos procedimentos que ajudaram na coleta de dados e, posteriormente, na análise dos resultados. Assim, o modelo proposto, desenvolvido através de softwares de geoprocessamento, ao ser comparado com o modelo de Prefeitura Municipal de Ponta Grossa, possibilitou a ampliação de novos olhares para novos locais de práticas de
\end{abstract}


esporte e lazer neste município, ao identificar locais diferentes daqueles apontados pela prefeitura.

Palavras-chave: esporte, lazer, mapeamento.

\section{Abstract}

This study sought to describe the process of building up a methodology for research on sports practice and leisure activities spaces mapping in Ponta Grossa - Paraná. To achieve this aim, we decide to adopt an interdisciplinary approach to make possible different procedural arrangements. Therefore, dialogue, mainly between the areas of physical education and geography was fundamental to reach the procedures that helped data collections and, later on, the analysis of results. Thus, the model proposed, developed using geoprocessing software, to be compared to the Ponta Grossa Town Hall model, enabled the extension of new looks at the local sports practice and leisure activities spaces in the city, by identifying different places from those pointed out by the town hall.

Keywords: sports, leisure, mapping.

\section{Introdução}

O Grupo de Pesquisa Esporte, Lazer e Sociedade (GEELASO), inserido no Programa de Pós-Graduação em Ciências Sociais Aplicadas (PPCSA), mestrado e doutorado com a área de concentração em Cidadania e Políticas Públicas, da Universidade Estadual de Ponta Grossa (UEPG), busca o intercâmbio de estudos e pesquisas interdisciplinares na área do esporte e do lazer, vinculado à linha de pesquisa História, Cultura e Cidadania.

Atualmente, o grupo está desenvolvendo um mapeamento dos espaços de esporte e lazer do Município de Ponta Grossa - Paraná1, visto que o mesmo pode ser compreendido como elemento fundamental, articulador e ordenador da sociedade. Para tanto, utilizou ferramentas de diversas áreas do conhecimento, de forma a desenvolver uma metodologia própria para a realização da pesquisa, conforme será descrito neste artigo.

Participam do grupo discentes de graduação, mestrado e doutorado (PPCSA), assim como voluntários de diversas formações acadêmicas, tais como Ciências Sociais, Direito, Educação Física, Geografia, História e Música. Essa diversidade de formações acadêmicas possibilita um diálogo interdisciplinar ${ }^{2}$ nos trabalhos desenvolvidos pelo grupo. Através desse olhar interdisciplinar, proporcionado pela participação de integrantes de diferentes áreas de conhecimentos, o grupo busca pelo projeto de mapeamento verificar as necessidades e características de cada localidade da cidade.

No que se refere aos espaços e equipamentos de esporte e lazer no município, será utilizado como base a localização dos mesmos disponibilizada pela prefeitura, por

\footnotetext{
1 A região dos Campos Gerais do Paraná é composta por 26 municípios e abrange uma área total de 28 mil quilômetros quadrados, com aproximadamente 1 milhão de habitantes. A economia da região é diversificada, com destaque para os setores madeireiro, metalmecânico e agropecuário. Cidades dos Campos Gerais são recordistas nacionais em vários segmentos do agronegócio. É aqui que está a maior e melhor bacia leiteira e o maior produtor de trigo do Brasil. Os Campos Gerais é composto pelas seguintes cidades: Arapoti, Balsa Nova, Campo do Tenente, Campo Largo, Cândido de Abreu, Carambeí, Castro, Curiúva, Imbaú, Imbituva, Ipiranga, Ivaí, Jaguariaiva, Lapa, Ortigueira, Palmeira, Piraí do Sul, Ponta Grossa, Porto Amazonas, Reserva, Rio Negro, São João do Triunfo, São José da Boa Vista, Sengés, Telêmaco Borba, Teixeira Soares, Tibagi, Ventania.

2 Para Japiassu $(1975$, p. 75) "[...] a interdisciplinaridade se caracteriza pela intensidade das trocas entre especialistas e pelo grau de integração real das disciplinas, no interior do projeto específico de pesquisa".
} 
meio do GeoPortal ${ }^{3}$. Nesse sentido, compreende-se que a análise dos diferentes espaços disponíveis na cidade é fundamental para a compreensão do mundo contemporâneo. Visto que para Santos (1988) o espaço é uma produção humana, condicionante e condicionado, ou seja, um conjunto indissociável em que participam objetos geográficos, naturais e sociais.

Ressalta-se ainda que, em relação aos dados disponibilizados pelo GeoPortal, estes são considerados pela prefeitura apenas aqueles espaços considerados formais, tais como academias, campos de futebol, quadras poliesportivas, parques e praças. Mas não há uma caracterização daqueles considerados informais, tais como campos de várzea, como pode ser observado na descrição sobre os equipamentos de esporte e lazer no Plano Diretor de Ponta Grossa:

Em relação a equipamentos esportivos e de lazer, a cidade conta com 5 estádios de futebol, 21 ginásios esportivos, 9 piscinas locais, 10 mini-ginásios esportivos, 62 campos de futebol, 9 campos de grama sintética, 3 pistas de skate, 18 praças públicas, além do Complexo Esportivo Governador Manoel Ribas (2006, p. 114).

Diante deste quadro, a união do conhecimento de diferentes áreas, por meio de um diálogo interdisciplinar, possibilitou o desenvolvimento de uma proposta metodológica de mapeamento dos diversos espaços de esporte e lazer do município, indo além daqueles espaços já catalogados no GeoPortal. Destaca-se ainda que esta característica poderá auxiliar na construção de novas estratégias governamentais e de políticas públicas relacionadas ao esporte e lazer em Ponta Grossa. Tem-se como objetivo, então, apresentar a construção dessa proposta metodológica, assim como contextualizar o leitor acerca da realidade do município, e demonstrar os primeiros resultados obtidos. Neste sentido, pretende-se realizar uma aproximação entre a universidade e o contexto do município, assim como com os órgãos do governo responsáveis pela manutenção, desenvolvimento e promoção destas iniciativas, com o objetivo de contribuir para uma melhora nas ações realizadas nas comunidades locais.

\section{Apontamentos iniciais sobre a categoria espaço, o esporte e o lazer}

O desenvolvimento de uma metodologia de mapeamento de espaços de esporte e lazer demanda a discussão do conceito de espaço, espaço público e lugar. Além desses conceitos, público e privado também são essenciais para o delineamento desta metodologia, visto a tensão existente entre estes, e sua relação direta com o com 0 conceito espaço. Assim, entende-se público e privado da seguinte forma:

Público. [Do lat. publicu.] 1. Relativo, pertencente ou destinado ao povo, à coletividade [...] 2. Relativo ou pertencente ao governo de um país [...] 3. Que é do uso de todos; comum [...] (FERREIRA, 1975, p.1156).

Privado. [Part. de privar.] Adj. 1. Que não é público; particular. (FERREIRA, 1975, p.1139).

A relação entre o público e o privado mostra-se, com base na citação anterior, dialética. Arendt (2007), ao relacionar as duas esferas realiza a seguinte diferenciação: associa o privado às necessidades e sentimentos humanos, é onde o sujeito busca atender suas necessidades vitais básicas, garantindo sua sobrevivência. Por outro lado, o espaço público, seria a sua conexão com mundo, onde se realizam suas atividades

3 O GeoPortal possui como objetivo disponibilizar informações georreferenciadas e tabulares sobre o município de Ponta Grossa para a comunidade, por meio do acervo de arquivos em diversos formatos. O mesmo está disponível para acesso pelo link <http://geo.pg.pr.gov.br/portal/>. 
sociais, lugar da fabricação dos objetos que garantem não somente sua reprodução, mas a do próprio mundo.

O espaço, então, é percebido nesta pesquisa como um importante instrumento para a compreensão da realidade, e não apenas como um palco inerte, onde os indivíduos executam suas ações. Parte-se, a partir desse ponto de vista, das colocações de Santos (1988), ao afirmar que o espaço não é apenas um reflexo da sociedade, nem apenas um fato social. O espaço deve ser considerado um conjunto indissociável em que participam objetos geográficos, naturais e sociais, bem como a sociedade em movimento.

Assim, o espaço geográfico pode ser primordialmente dado, mas sua organização e sentido são produtos da transformação e experiências sociais. Nesse âmbito, conforme afirma Lefebvre (2013), a relação social ocorre no âmbito espacial, de forma que este constitui o meio em que se realizam as relações sociais. De forma que o espaço é social e intrínseco à existência, no sentido que as pessoas fazem os lugares, e os lugares fazem as pessoas.

Atrelado ao conceito de espaço há o conceito de lugar (TUAN, 2013), sendo ambos componentes do mundo vivo. Tal conceito está relacionado à apropriação do espaço, tal que por meio desta, o espaço se transforma em lugar, perpassado por experiências e vivências. "O lugar representa a segurança, enquanto o espaço representa a liberdade", de forma que estamos ligados ao lugar, mas desejamos a liberdade do espaço (TUAN, 2013, p.72). As concepções de espaço e lugar, então, não devem ser definidas uma sem a outra.

A categoria espaço, especialmente no âmbito desta pesquisa, demanda também uma discussão acerca da dicotomia entre público e privado. Assim como há uma relação estreita entre os conceitos de espaço e lugar, o significado de espaço público também está associado ao "lugar", visto que pode ser conceituado como o local onde as afinidades sociais e as diferenças são vivenciadas (GOMES, 2014).

Para Carlos (2011), o lugar apresenta-se como condição de realização da vida cotidiana, o que envolve a articulação espaço-tempo pelos usos do lugar. Nas palavras da autora: "a relação entre o habitante e a cidade pela vida cotidiana se realiza como ação relacionada às possibilidades e aos limites do uso do lugar, em determinado momento histórico" (CARLOS, 2011, p. 34). Pode-se afirmar, então, que o processo da produção da vida ocorre através das formas de apropriação do espaço.

Nessa mesma direção, as diferentes formas de utilização dos espaços de esporte e lazer de uma cidade, dotam a estes uma dimensão qualitativa, ao ponto que estes (o esporte e o lazer) são fenômenos culturais, que trazem junto a si uma gama de significações. Nesse momento, vale ressaltar que, no desenvolvimento da pesquisa in loco, não foram apresentados aos pesquisadores elementos que caracterizassem um determinado local enquanto espaço público ou privado, bem como de esporte ou lazer. Isso propiciou uma amplitude sobre a compreensão destes espaços, ao não realizar uma predeterminação sobre quais características deveriam ser analisadas, como poderá ser identificado no desenvolvimento do artigo, ao serem identificados espaços públicos e privados. Ressalta-se, ainda, que a Prefeitura Municipal de Ponta Grossa, por meio do GeoPortal, identifica e mapeia espaços de esporte e lazer públicos e privados.

\section{O relato de experiência}

\subsection{O contexto do município de Ponta Grossa}

Partindo da compreensão que o espaço é um elemento essencial para a compreensão da realidade, e as práticas desenvolvidas no mesmo estão relacionadas com seu contexto, são necessárias algumas informações para o desenvolvimento da proposta metodológica. 
A contextualização do município mostra-se, então, um elemento essencial para o processo de construção da metodologia. Para tanto, foi realizado um apanhado do histórico do município, assim como, dados secundários, ou seja, aquele que se referem a informações pré-existentes, coletadas por outras instituições com objetivos diferenciados em relação ao estudo em desenvolvimento (MINAYO, 2012).

O município de Ponta Grossa, foco da pesquisa, se localiza no Estado do Paraná, no segundo Planalto Paranaense, na região dos Campos Gerais ${ }^{4}$. De acordo com o Instituto Brasileiro de Geografia e Estatística (IBGE) (2010), estima-se que a população da cidade, em 2015, se dava em torno de 311.611 habitantes, a $4^{\text {a }}$ maior do estado. $O$ Índice de Desenvolvimento Humano (IDH), em Ponta Grossa, atinge a marca de 0,763, sendo o décimo quinto município no ranking das 20 cidades com maior IDH no Estado (IBGE, 2010). Ressalta-se ainda que o município é a $5^{\text {a }}$ maior economia do estado, ficando atrás de Curitiba (capital), São José dos Pinhais, Londrina e Maringá.

Para compreender o contexto urbano e social a pesquisa se encontra, é importante apresentar como se delineou a formação e estruturação da cidade de Ponta Grossa. Nascimento (2008) realiza uma descrição que introduz de maneira clara esse processo:

A evolução urbana de Ponta Grossa ocorreu em conformidade com sua trajetória econômica. De acordo com Santos (2002), durante os séculos XVIII e XIX a população ponta-grossense se encontrava, em sua maioria, nas áreas rurais dos municípios, residindo em fazendas e colônias de imigrantes europeus. No século XX, porém, a evolução do processo de urbanização levou a maior parte de seus habitantes, já nas primeiras décadas daquele século, a se concentrar predominantemente na cidade. Desde então, a produção do espaço urbano local vem apresentando uma dinâmica bastante intensa, com transformações importantes em sua estrutura interna, nos modos de expansão urbana e de utilização dos fragmentos do espaço (NASCIMENTO, 2008, p.42).

O povoado que viria a receber posteriormente a denominação de Ponta Grossa, surgiu em função de sua situação privilegiada na encruzilhada dos caminhos dos tropeiros. Na última década do século XIX, Ponta Grossa passou por transformações significativas com a chegada de duas ferrovias - Estrada de Ferro do Paraná e Estrada de Ferro São Paulo - Rio Grande, elevando-a à condição de principal cidade dos Campos Gerais.

No início do século XX, Ponta Grossa se abriu para uma nova fase: as indústrias impulsionaram a economia local, absorvendo expressiva mão-de-obra, e ocasionando um processo de migração intenso do interior do Paraná em sua direção. O rápido aumento populacional, e a incapacidade do poder público em resolver os problemas decorrentes da grande demanda, configuraram as atuais formas de ocupação urbana, com pressão na área central e formação de diversos núcleos habitacionais periféricos.

A expansão da cidade, a partir desse período, deu-se em formato 'tentacular' (NASCIMENTO, 2008). Para compreendermos a geografia do município, façamos um percurso histórico da composição da cidade. De acordo com Nascimento (2008), a expansão de Ponta Grossa e a fragmentação em bairros, de uma forma sucinta, deu-se a partir da década de 1920. Neste período a organização da cidade começa a passar por

\footnotetext{
${ }^{4}$ A região dos Campos Gerais do Paraná é composta por 26 municípios e abrange uma área total de 28 mil quilômetros quadrados, com aproximadamente 1 milhão de habitantes. A economia da região é diversificada, com destaque para os setores madeireiro, metalmecânico e agropecuário. Cidades dos Campos Gerais são recordistas nacionais em vários segmentos do agronegócio. É aqui que está a maior e melhor bacia leiteira e o maior produtor de trigo do Brasil. Os Campos Gerais é composto pelas seguintes cidades: Arapoti, Balsa Nova, Campo do Tenente, Campo Largo, Cândido de Abreu, Carambeí, Castro, Curiúva, Imbaú, Imbituva, Ipiranga, Ivaí, Jaguariaiva, Lapa, Ortigueira, Palmeira, Piraí do Sul, Ponta Grossa, Porto Amazonas, Reserva, Rio Negro, São João do Triunfo, São José da Boa Vista, Sengés, Telêmaco Borba, Teixeira Soares, Tibagi, Ventania.
} 
uma 'disciplinarização' do espaço urbano. Os bairros dividiam-se em: lugares para trabalhar, para morar e para lazer.

Nessa mesma época, o Centro era ocupado por moradias de classes altas, e possuía a melhor infraestrutura. Com a expansão da linha férrea nas regiões mais afastadas, surgem os bairros de Uvaranas (região leste) e Oficinas (região sul). Em 1930, houve a expansão da região norte da cidade, e surgiram bairros residenciais com poucos serviços e algum comércio, tais como o Orfãs, Nova Rússia e Ronda.

$\mathrm{Na}$ década de 1940 o bairro Uvaranas se expandiu no sentido bairro-centro, e a região começou a abrigar moradores e pequenos comércios. Foram nas duas décadas seguintes (1950 e 1960) que Ponta Grossa tem seu marco da expansão territorial, de forma horizontal, a partir da especulação fundiária que crescia na época. Nos anos 1960, com a urbanização crescente a modernização, surge outro bairro na cidade: o Cará-Cará. Este, destinado a ser a área industrial do município, ficando relativamente afastado das áreas residenciais.

Na década de 1970 surgem os condomínios habitacionais: grandes expansões de terras para fins de urbanização. Vale dizer que entre a década de 1960 a 1980 surgiram grandes conjuntos habitacionais na área nordeste, como o núcleo Monteiro Lobato (bairro Jardim Carvalho), o 31 de março (Bairro Neves) na área noroeste, e Santa Paula 1, à Oeste.

Durante os anos 1970 e 1980, com a grande concentração de pessoas e circulação de habitantes no centro, deixaram suas residências unifamiliares para se instalarem em localidades próximas ao centro. Assim nascem os novos bairros residenciais da classe alta de Ponta Grossa, dos quais podemos citar Estrela (Vilas Jardim América, Estrela e Dona Ida), Jardim Carvalho (Vilas Jardim Carvalho I, Esmeralda e Jardim San Diego), e parte do bairro Neves. Na década de 1980 a cidade toma o formato que se perpetua até os dias atuais.

O Plano Diretor do Município, desenvolvido em 2006, afirma que o adensamento da malha urbana permanece no centro e em seu entorno. Atualmente o município de Ponta Grossa divide-se em 16 bairros, são eles: Estrela, Boa Vista, Jardim Carvalho, Cará-Cará, Centro, Contorno, Piriquitos, Chapada, Neves, Nova Rússia, Órfãs, Ronda, Olarias, Uvaranas, Colônia Dona Luiza, Oficinas.

É importante apresentar, que atualmente, Ponta Grossa possui o Índice de Desenvolvimento Humano Municipal (IDH-M) de 0,763, mais alto que a média do Estado, que é de 0,749. Esse índice é composto por três dimensões do desenvolvimento humano: a oportunidade de viver uma vida longa e saudável (IDHM Saúde); de ter acesso ao conhecimento (IDHM Educação) e ter um padrão de vida que garanta as necessidades básicas (IDHM Renda).

As informações levantadas acerca do município, tanto históricas quanto relacionadas a seus indicadores sociais e econômicos, corroboram para a discussão da construção dos aspectos procedimentais da metodologia, que serão demonstrados em seguida. Questiona-se em que ponto que a existência e distribuição dos espaços de esporte e lazer podem estar relacionados à tais indicadores dentro de Ponta Grossa. Bem como compreende-se que a existência dos mesmos corrobora para uma vida de qualidade.

\subsection{Aspectos procedimentais}

Para a realização do mapeamento aqui apresentado, foi necessário o diálogo interdisciplinar com outras áreas do conhecimento. Dessa forma, o relato da construção do percurso metodológico do núcleo será exposto, evidenciando as opções teóricas, e os procedimentos utilizados. 
A partir das informações acerca dos espaços de esporte do município, disponibilizadas pelo GeoPortal, foram levantados a relação dos equipamentos esportivos por bairro. Essa informação permitiu realizar uma divisão de como estes espaços estão inseridos no município. Destaca-se a partir desses dados que dos 130 espaços de esportes identificados pela prefeitura, os bairros que possuem um maior número destes, são Uvaranas e Jardim Carvalho, com 20 e 14 espaços, respectivamente. Ressalta-se que a prefeitura não apresenta dados em relação a espaços de lazer, ou esporte e lazer, demonstrando a importância do levantamento dessas informações pelo GEELASO.

A partir dos dados disponibilizados no GeoPortal, para determinar de que forma os bairros seriam percorridos para a realização da pesquisa, primeiramente, recorreu-se ao Instituto Brasileiro de Geografia e Estatística - IBGE. Nele, buscou-se informações e procedimentos do Censo Demográfico 2010. O Censo possui uma metodologia própria, composta por dois tipos de questionário (básico e de amostra) a serem aplicados nas residências e pela coleta de dados. Baseou-se essencialmente no método de coleta de dados proposto pelo IBGE (2010): o setor censitário.

Compreende-se setores censitários como unidades territoriais do Censo Demográfico do IBGE, estabelecidos para fins de controle cadastral, formados por área contínua, situada em único quadro urbano ou rural, com dimensão e número de domicílios que permitam o levantamento por um pesquisador. Para iniciar o mapeamento dos espaços e equipamentos de esporte e lazer em Ponta Grossa, foi necessário determinar inicialmente um setor censitário a ser pesquisado. Conjuntamente, a partir dos dados disponíveis no GeoPortal, buscou-se desenvolver um procedimento para balizar quais setores censitários, e em qual ordem, a pesquisa se delinearia.

Por uma questão de segurança aos pesquisadores, inicialmente, optou-se por buscar, inicialmente um ator social dentro dos bairros Uvaranas e Jardim Carvalho (aqueles com maior número de espaços de esporte identificados pela Prefeitura Municipal de Ponta Grossa), a fim de compreender a dinâmica dos mesmos, assim como para amparar os pesquisadores durante o trabalho de campo. Para tanto, utilizou-se como procedimento metodológico a 'Bola de Neve' ou 'snowball'.

A 'Bola de Neve' ou 'snowball' consiste em uma técnica em que um ator social pesquisado indica outro participante do processo. Ou seja, um sujeito participante da pesquisa indica outro para a participação, formando uma espécie de 'teia'. Diante da inexistência de um cadastro com informações do universo a ser pesquisado, será possível aproximar do conjunto do grupo alvo (COLEMAN, 1958; GOODMAN, 1961).

Neste sentido, segundo Goodman (1961) é importante que as 'sementes', os primeiros participantes selecionados, exerçam o papel de liderança no lócus estudado, que conheçam os membros da comunidade, para que possam indicar novos participantes, 'filhos' ou 'frutos', como são chamados, que contribuam efetivamente com a investigação. Por esta razão, na pesquisa piloto, selecionou-se um membro da associação de moradores do bairro Jardim Carvalho como ator social.

O percurso até o membro da associação de moradores teve início dentro dos encontros do GEELASO, onde os participantes foram questionados se conheciam algum ator social de relevância dentro dos bairros Jardim Carvalho e Uvaranas. Nesse momento, um dos participantes comunicou que, por residir no Jardim Carvalho, poderia auxiliar buscando entrar em contato com algum participante da associação de moradores do bairro. Para tanto, entrou em contato com um vizinho mais antigo no bairro, que o indicou até outro, e sucessivamente até conseguir entrar em contato com o ator social que foi o presidente da 'associação de moradores do bairro Jardim Carvalho. O mesmo nos auxiliou a determinar em qual local do bairro poderíamos realizar a pesquisa piloto, especialmente em relação à segurança dos participantes.

A priori, a partir da determinação do ator social, foi estabelecido o setor censitário número 411990505000023, inserido no bairro Jardim Carvalho, do município de Ponta 
Grossa, a fim de ser utilizado como 'campo teste'. Como vimos anteriormente, este bairro foi criado entre as décadas de 1970 e 1980. De acordo com o censo do IBGE (2010), a população total da localidade é de 22.393 habitantes, dos quais 10.744 são homens e 11.649 são mulheres. No censo de 2000, divulgado pelo IBGE, o Jardim Carvalho possuía 15.152 habitantes. Comparativamente, a localidade cresceu cerca de 51,74\%.

Ressalta-se, nesse âmbito, a importância de compreender o contexto social do espaço a ser analisado, visto que o espaço constitui uma realidade objetiva, um produto social em um processo constante de transformação. Ou seja, o espaço impõe uma realidade própria, e para investigá-lo, é relevante apreender sua relação com a sociedade (SANTOS, 2006).

Para percorrer a área delimitada foi utilizada a metodologia do IBGE de 'Percurso do Setor Censitário', compreendida pela instituição como:

[...] o procedimento utilizado para andar em uma determinada área, de forma disciplinada e cuidadosa, para que não se deixe de visitar nenhum dos endereços, nem de registrar nenhuma unidade como domicílio, estabelecimento ou edificação em construção. Nesta pesquisa, essa área é o Setor Censitário (IBGE/MANUAL DO RECENSEADOR, 2010, p. 83).

Utilizando como referência essa metodologia desenvolvida pelo IBGE, foram determinadas rotas a serem percorridos pelos pesquisadores, de modo a cobrir toda a área do setor censitário determinado. Vale ressaltar que as rotas foram divididas usando as ruas como referência.

Os participantes do GEELASO foram divididos em duplas, totalizando sete grupos, distribuindo as rotas definidas por meio de 'sorteio aleatório', objetivando uma distribuição neutra das atividades. A saída de campo aconteceu no dia 22/07/2015, às 14h00min, em frente ao Campus Central da Universidade Estadual de Ponta Grossa (UEPG).

Uma das demandas levantadas pelo grupo foi a elaboração de um formulário para auxiliar a coleta de dados nos locais de esporte e lazer da cidade encontrados durante a pesquisa de campo. Para tanto, no primeiro semestre de 2014, os membros do GEELASO iniciaram, durante os encontros do grupo, as discussões necessárias para a construção deste instrumento.

Algumas questões nortearam a elaboração do formulário de mapeamento, tais como: $O$ que pode ser considerado um espaço de esporte ou o lazer? Como realizar este levantamento? O que observar nestes locais? Que indivíduos frequentam estes locais?

Inicialmente o instrumento foi subdividido em quatro eixos: a 'Identificação' do local (Nome, endereço, setor censitário, localização GPS, entre outras informações). Seguido pelo eixo 'Infraestrutura do Local', o qual busca descrever se o mesmo é um ginásio, um campo ou uma praça, por exemplo. Em busca de levantar mais informações acerca do local mapeado, as quais auxiliaram na percepção das especificidades e necessidades do lugar presentes no eixo 'Características do espaço' (se o local é público ou particular, como ocorre a manutenção do espaço, como é o acesso, quais os equipamentos, pontos de referências e limpeza/serviços) e por fim as 'Características do usuário', que nos possibilitaram verificar qual o público destes locais.

Após a elaboração deste primeiro formulário, os membros do núcleo realizaram as primeiras saídas in loco, no Setor censitário 411990505000023, com o objetivo de testar o instrumento para realizar posteriormente novas reflexões sobre os aspectos positivos e negativos encontrados, assim como avaliar a necessidade de inserção de novos elementos ao formulário ou retirada de outros itens. Este processo, de saídas de campo para levantamento dos locais, armazenamento dos dados e discussões sobre as possíveis adaptações ao formulário, perdurou por todo o segundo semestre de 2014.

Neste sentido, nos primeiros encontros do núcleo em 2015, os membros do grupo em conjunto, acrescentaram um item denominado 'Percepção dos observadores', dando a 
possibilidade de descrição do local, que ampliam o potencial de análise dos dados, não deixando as anotações restritas às primeiras categorias do formulário.

O grupo vem buscando a cada experiência, seja, nas saídas de campo ou nos encontros na universidade, o aperfeiçoamento do formulário, que serviu de base para todo o processo de mapeamento dos locais de esporte e lazer da cidade de Ponta Grossa.

A partir das informações levantadas sobre o município de Ponta Grossa, assim como sobre os setores censitários determinados pelo grupo e dados coletados em campo, por meio da aplicação do formulário desenvolvido pelo GEELASO, foram desenvolvidos mapas temáticos, utilizando os softwares de geoprocessamento 'AutoCAD Map' e 'TerraView Política Social' para a construção do mesmo, a fim de mapear e caracterizar a distribuição dos espaços de esporte e lazer no município de Ponta Grossa.

Compreende-se como 'mapa' as representações dos aspectos físicos, naturais e artificiais da superfície terrestre, destinado a fins culturais, ilustrativos e análises qualitativas ou quantitativas. São, assim, abstrações que nos ajudam a compreender nosso ambiente (PEREIRA, 2000). Nesse sentido, segundo Pereira e Silva (2001), a coleta e o processamento de informações geográficas assumiram um papel estratégico na administração, planejamento e pesquisa das cidades e regiões.

As tecnologias de geoprocessamento, também conhecido como GIS (Geographical Information Systems) ou SIG (Sistema de Informações Geográficas), são essenciais nesse processo, visto que permitem, por meio da utilização de programas de computador, o uso de informações cartográficas (mapas e plantas) juntamente a dados que possam associar coordenadas a esses mapas ou plantas. O componente mais importante do Geoprocessamento, então, é a base de dados, as quais contém os dados que representam um modelo do mundo real, possibilitando extrair informações do sistema. Conforme Pereira e Silva (2001), esta base é formada, geralmente, por informações provenientes de fontes diversas, tais como levantamentos cadastrais, censos, imagens de sensoriamentos remotos, mapas, dentre outros. A componente base de dados é a chave do sistema de geoprocessamento, visto que reflete a representação da realidade. Neste caso, a base de dados deve conter dados que permitam representar a cidade de Ponta Grossa, e seus espaços de esporte e lazer.

O mapa base de Ponta Grossa foi construído a partir de informações cartográficas disponibilizadas pela Prefeitura Municipal de Ponta Grossa (GeoPortal), e pelo Instituto Brasileiro de Geografia e Estatística - $\mathrm{IBGE}^{5}$, utilizando o software AutoCAD Map. De forma que o mesmo foi composto pelo limite de bairros, município e quadras, disponibilizado pela prefeitura, e pela divisão de setores censitários desenvolvida pelo IBGE. Ressalta-se que foi utilizado o Universal Transversa de Mercator (UTM) como projeção cartográfica no desenvolvimento do mapa ${ }^{6}$.

A partir deste mapa base, informações referentes aos espaços de esporte e lazer do município, tanto disponíveis no GeoPortal, assim como coletadas na pesquisa de campo por meio da aplicação dos formulários, constituiram um novo mapa. Nesse âmbito, vale ressaltar que as localizações dos espaços (pontos georreferenciados), durante a pesquisa de campo, foram determinadas utilizando o aplicativo disponível para smartphones e tablets "C7 GPS dados", desenvolvido pela Universidade Federal de Santa Maria.

\section{Resultados do projeto piloto}

5 Disponível no site: <http://mapas.ibge.gov.br/bases-e-referenciais/bases-cartograficas/malhas-digitais>.

6 O UTM é um sistema de coordenadas baseado no plano cartesiano (eixo x,y) e usa o metro como unidade para medir distâncias e determinar a posição de um objeto. Para tanto, o globo é dividido em 60 fusos distintos que representam a superfície da Terra. O Município de Ponta Grossa encontra-se no fuso no 23. 
A aplicação dos formulários pelos participantes do GEELASO durante a pesquisa de campo, e as informações provenientes deste, possibilita a constituição de um banco de dados sobre os espaços de esporte e lazer de Ponta Grossa.

Algumas informações registradas no primeiro eixo do formulário, denominado como 'Identificação', buscam coletar informações tais como: nome do local, endereço, número, bairro, setor censitário e a localização UTM de forma a criar uma base de dados dos espaços de esporte e lazer do município de Ponta Grossa. Esta base de dados, pode possibilitar o cruzamento de informações com aquelas disponibilizadas pela prefeitura Municipal de Ponta Grossa.

Além de informações sobre arruamento, limite do município e divisas de bairros, a prefeitura de Ponta Grossa também apresenta informações cartográficas em relação a escolas, espaços esportivos e zoneamento da cidade, dentre outras ${ }^{7}$. No âmbito da pesquisa em questão, foram somadas ao mapa informações referentes ao esporte do município de Ponta Grossa, disponibilizadas no banco de dados do GeoPortal. No que se refere às informações disponibilizadas em relação aos espaços esportivos, vale destacar que, apesar da denominação espaços esportivos estes podem se enquadrar também enquanto espaços de lazer, conforme o caráter que os mesmos são utilizados pela população. A Figura 1 demonstra, a partir destes dados, de que forma os espaços de esporte se inserem nos bairros de Ponta Grossa:

Figura 1: Bairros do município de Ponta Grossa e espaços de esporte identificados pela Prefeitura Municipal de Ponta Grossa

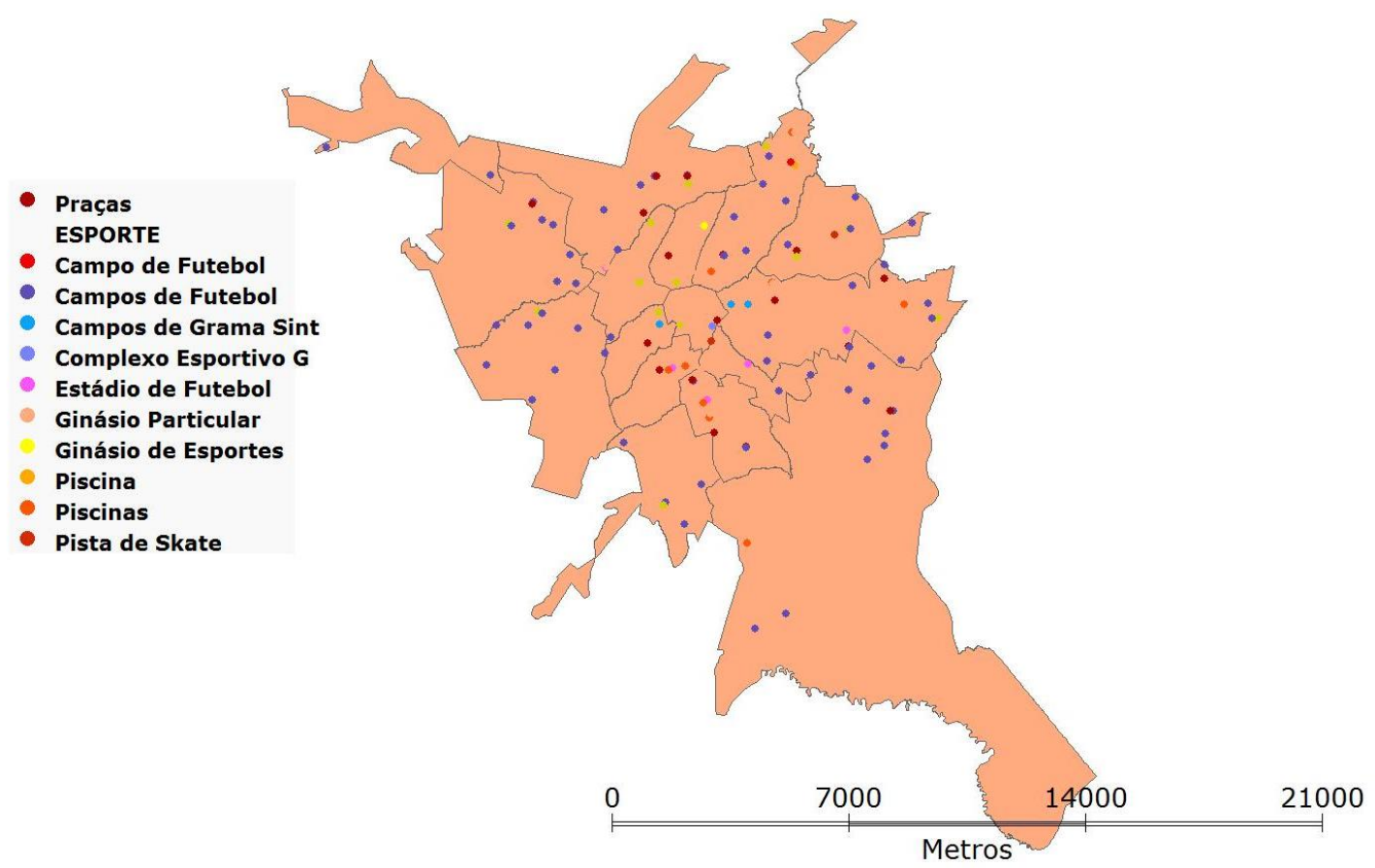

Fonte: Prefeitura Municipal de Ponta Grossa/GeoPortal Ponta Grossa (2008)

Com base em informações disponibilizadas pela Prefeitura de Ponta Grossa e IBGE, somadas às coletadas na aplicação do questionário e inseridas dentro do software AutoCAD Map foi possível desenvolver um mapeamento dos espaços de esporte e lazer, formais e informais, existentes no município. Em um segundo momento foi utilizado o software TerraView Política Social, a fim de realizar uma triangulação dos dados.

\footnotetext{
7 Tais como quadras, logradouros, bairros, loteamentos, equipamentos de segurança e saúde pública, censo, equipamentos de táxi e trânsito, patrimônio cultural e natural.
} 
A Figura 1 e a Figura 2 demonstram a relação entre as informações apresentadas pela prefeitura e aquelas levantadas pelo grupo a partir do trabalho de campo, respectivamente, acerca do setor censitário determinado para a pesquisa piloto.

Figura 2: Mapa do Setor Censitário 411990505000023 e seus espaços de esporte e lazer, segundo a Prefeitura Municipal de Ponta Grossa

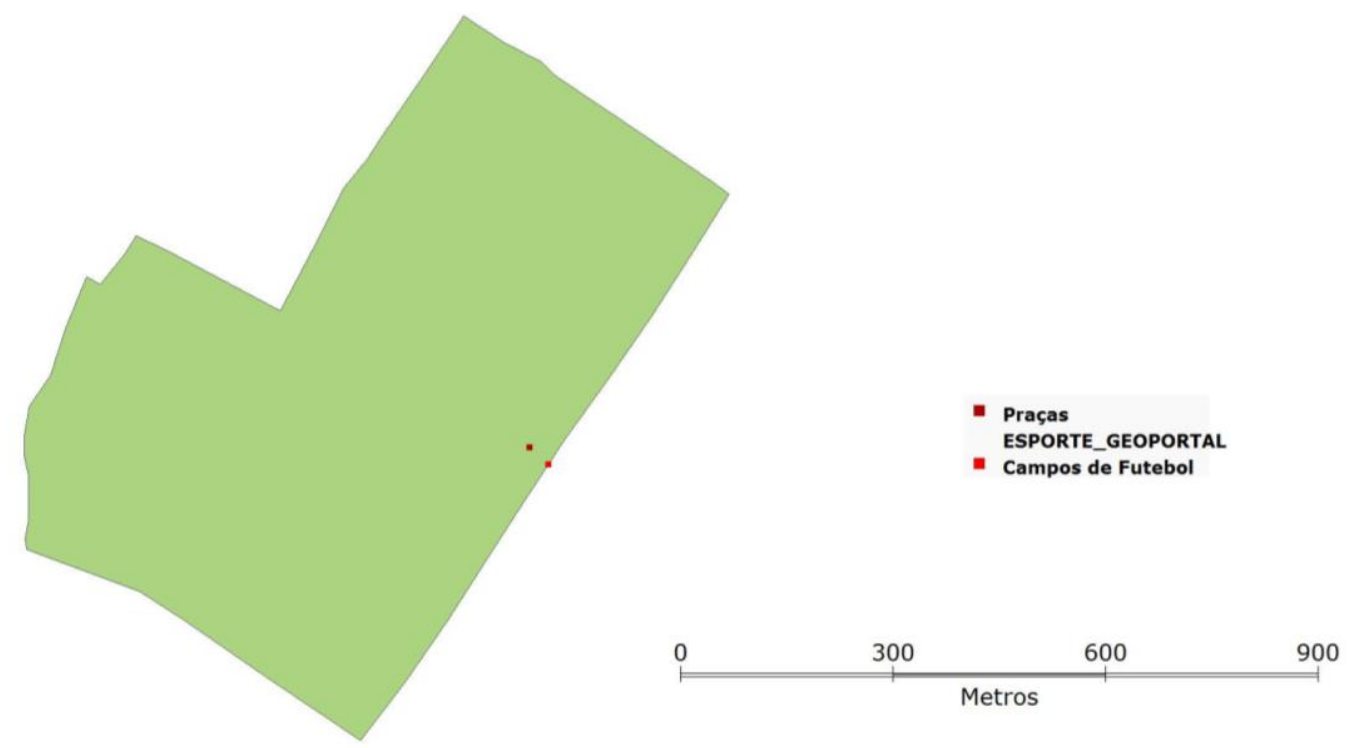

Fonte: IBGE (2010); Prefeitura Municipal de Ponta Grossa/GeoPortal Ponta Grossa (2008)

Figura 3: Mapa do Setor Censitário 411990505000023 e seus espaços de esporte e lazer levantados na pesquisa de campo

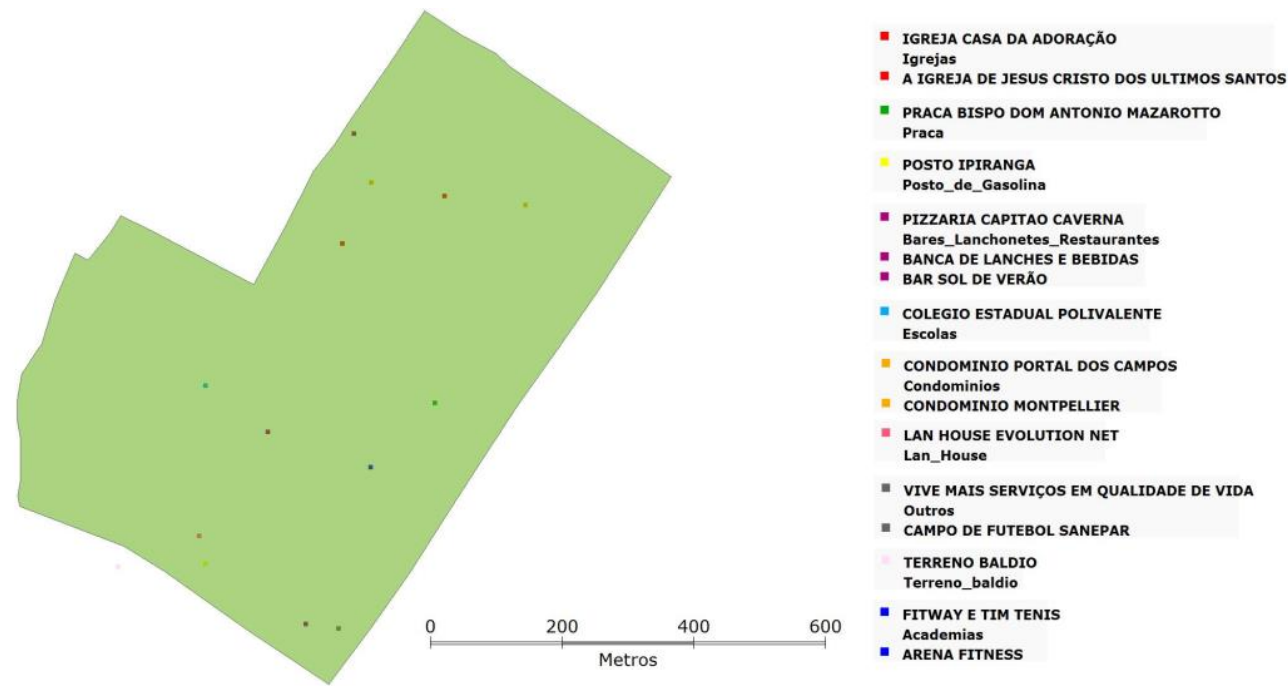

Fonte: IBGE (2010); Pesquisa de campo (2015)

A partir da triangulação entre os dados disponibilizados pelo GeoPortal, e aqueles coletados na pesquisa de campo, pode-se perceber uma dissonância entre os espaços de esporte e lazer identificados. Enquanto o GeoPortal identificou um campo de futebol e uma praça no setor censitário determinado, os pesquisadores consideraram outros espaços. Nos dados coletados durante a pesquisa de campo, não foi identificado o campo de futebol, mas, além desse espaço, foram compreendidos como espaços de esporte e 
lazer: academias, quadras esportivas, igrejas, escolas, bares, lanchonetes e restaurantes, condomínios, lan house, terrenos baldios e áreas de conveniência em postos de gasolina. A Figura 4 busca explicitar essa dissonância entre as informações.

Figura 4: Mapa do Setor Censitário 411990505000023 e seus espaços de esporte e lazer, a partir da triangulação dos dados

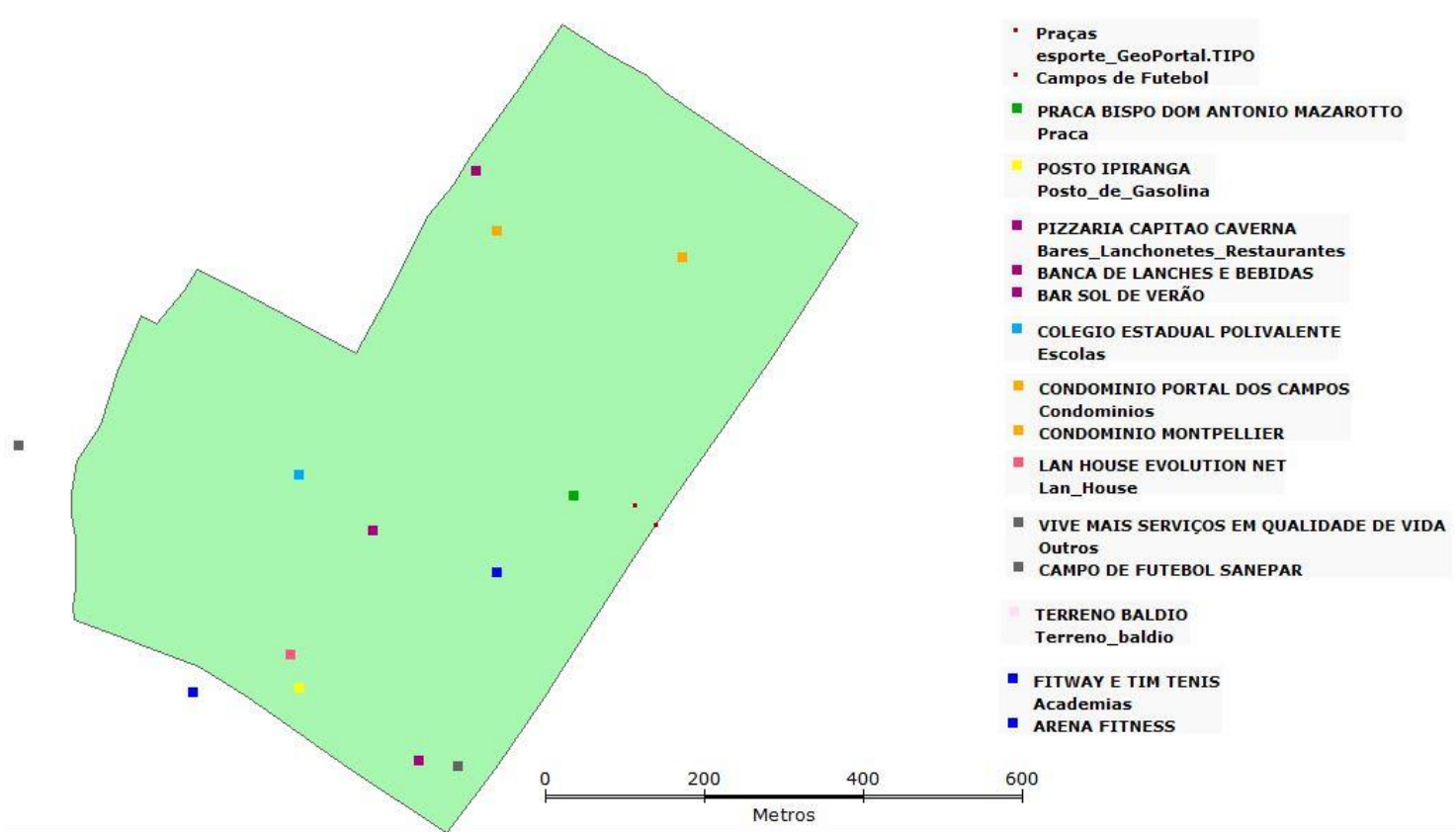

Fonte: IBGE (2010); Prefeitura Municipal de Ponta Grossa/GeoPortal Ponta Grossa (2008); Pesquisa de campo (2015)

Essa diferença entre os dados oficiais, e aqueles levantados a partir da pesquisa de campo, demonstra a multiplicidade de olhares que estão perpassando 0 desenvolvimento da pesquisa. Nesse âmbito, é válido colocar que, no início do desenvolvimento do mapeamento, não foram realizadas discussões no GEELASO acerca de quais conceitos de esporte e lazer seriam norteadores para a pesquisa. Esse aspecto, atrelado ao caráter interdisciplinar dos participantes da pesquisa, possibilitou diferentes olhares e concepções sobre o que são espaços de esporte e lazer. Assim como esses diferentes olhares subsidiaram o grupo para definir espaços de estudo que compreendam a transformação de espaços indiferenciados em lugares.

Não obstante, destaca-se a importância das reflexões em grupo acerca da estruturação do formulário de mapeamento, para a construção de um instrumento que transcendesse a identificação dos locais. Deste modo, identificá-los geograficamente e estruturalmente, por meio da criação de mapas temáticos, torna-se o primeiro passo, essencial, deste processo. A descrição das "características do espaço" e "características do usuário" presentes no instrumento, permitem inúmeros debates em torno do uso destes espaços, que podem tornar-se locais, e de estratégias para seu melhor aproveitamento. 
Ressalta-se, ainda, que o desenvolvimento de um mapa com os espaços de esporte e lazer identificados corrobora para a visualização das formas que os mesmos estão inseridos dentro dos setores censitários, bairros e município. E como consequência, auxilia na análise e discussão dos dados levantados.

\section{Considerações finais}

A partir da compreensão que o espaço é um instrumento essencial para a análise e apreensão da realidade, a construção de uma metodologia de mapeamento dos espaços de esporte e lazer de Ponta Grossa mostra-se, com base nessa compreensão, uma ferramenta válida para a pesquisa no âmbito do esporte e lazer.

A interdisciplinaridade, característica marcante do GEELASO, corroborou de forma significativa na construção da metodologia de mapeamento dos espaços de esporte e lazer. No mesmo sentido, as diferentes compreensões levantadas acerca dos espaços esporte e do lazer trouxeram questionamentos ao longo do processo de construção das ferramentas, os quais foram essenciais para o desenvolvimento de uma metodologia além do "lugar comum". Assim como, possibilitou diferentes olhares da compreensão de espaços de esporte e lazer, indo além de quadras e praças, por exemplo.

A utilização dos setores censitários determinados pelo IBGE (2010), e a metodologia para a realização do 'Percurso do Setor Censitário' desenvolvida pela mesma instituição, nos guiou em relação à divisão do município para a realização do trabalho de campo. Após determinado este ponto, surgiu o questionamento de que forma os espaços e equipamentos de esporte e lazer encontrados seriam identificados e analisados. O 'Formulário de levantamento de locais de esporte e lazer em Ponta Grossa', desenvolvido conjuntamente pelo grupo, cumpriu essa função. O mesmo demonstra a heterogeneidade do grupo, ao ponto que busca identificar questões de geoprocessamento, características do local e seus equipamentos, assim como usuários presentes no momento da pesquisa, e descrições dos pesquisadores acerca do espaço/equipamento. No que se refere à percepção dos usuários presentes nos espaços de esporte e lazer no momento da pesquisa, está será a próxima etapa de pesquisa do grupo. A partir das informações levantadas no mapeamento, alguns espaços serão pesquisados com maior profundidade, buscando compreender sua dinâmica e as forças envolvidas.

Destaca-se ainda a necessidade de um instrumento formal de análise dos espaços e equipamento de esporte e lazer para orientar a análise, considerando que, conforme a formação acadêmica dos pesquisadores, há diferentes olhares sobre o mesmo ponto, podendo não ser percebidas algumas caraterísticas consideradas relevantes pelo grupo que compõe o GEELASO.

A utilização do geoprocessamento no mapeamento se configura, inicialmente, como apoio à pesquisa de campo, visto que auxilia na criação dos mapas dos setores, e determinação das rotas a serem utilizadas pelos pesquisadores. Em um segundo momento, após a coleta dos dados em campo, pode-se fazer o complemento destes dados com aqueles divulgados pela prefeitura, assim como criar um mapa com todos os pontos identificados pelos pesquisadores. $O$ geoprocessamento permite, dessa forma, um cruzamento dos dados de esporte e lazer, com informações sobre saúde, segurança, renda, dentre outras, de forma a realizar uma triangulação entre os diversos dados, primários e secundário. Esta triangulação permite uma compreensão mais ampla do contexto do município, auxiliando a construção de políticas públicas de esporte e lazer.

Ressalta-se, por fim, que foi apresentado no artigo em questão o relato das fases do desenvolvimento de uma metodologia de mapeamento, a qual ainda está em fase de realização e levantamento de dados. 


\section{Referências}

Sociais.

Diretoria de Pesquisas - DEP - Coordenação de População e indicativos $<$ http://cidades.ibge.gov.br/xtras/perfil.php?lang=\&codmun=411990\&search=||infogr\%E1fic os:-informa\%E7\%F5es-completas>. Acesso em: 11 de jan. de 2016.

Manual do Recenseador. Rio de Janeiro, 2010. Disponível em: <http://biblioteca.ibge.gov.br/visualizacao/instrumentos_de_coleta/doc2601.pdf>. Acesso em: 16 dez. 2015.

O Espaço Geográfico como Categoria Filosófica. Terra Livre / O Espaço em Questão, no 5, 1988.

Plano Diretor Participativo - Município de Ponta Grossa. Diagnóstico. 2006.

Disponível em: <http://geo.pontagrossa.pr.gov.br/portal/planodiretor/2.5.2_servicos_sociais.pdf>. Acesso em: 20 jan. 2016.

ARENDT, Hannah. A condição humana. Trad. Roberto Raposo. 10. ed. Rio de Janeiro: Forense Universitária, 2007.

CARLOS, Ana Fani Alessandri (org.). A produção do espaço urbano: agentes e processos, escalas e desafios. São Paulo: Contexto, 2011.

COLEMAN, James S. Snowball sampling: problem and techniques of chain referral sampling. Human Organization, v.17, p. 28-36, 1958.

FERREIRA, Aurélio Buarque de Holanda. Novo Dicionário da Língua Portuguesa. 1a ed. Rio de Janeiro: Editora Nova Fronteira, 1975.

GOMES, Paulo Cesar da Costa. A condição urbana: ensaios de geopolítica da cidade. 5 ed. Rio de Janeiro: Bertrand Brasil, 2014.

GOODMAN, Leo A. Snowball sampling. The Annals of Mathematical Statistics. v. 32, p. 148-170, 1961.

INSTITUTO BRASILEIRO DE GEOGRAFIA E ESTATÍSTICA - IBGE. Bases

cartográficas - Malhas Digitais. Disponível em: <http://mapas.ibge.gov.br/bases-e-

referenciais/bases-cartograficas/malhas-digitais>. Acesso em: 15 dez. 2015.

LEFEBVRE, Henri. La producción del espacio. Madrid: Capitán Swing Libros, 2013.

MINAYO, Maria Cecília de Souza (org.). Pesquisa social: teoria, método e criatividade. Petrópolis, RJ: Vozes, 2012.

NASCIMENTO, Ederson. Espaço e desigualdades: mapeamento e análise dinâmica de eclusão/inclusão social na cidade de Ponta Grossa. Dissertação (Mestrado em Gestão do Território). Ponta Grossa, 2008, 173 f. Programa de pós-graduação em Geografia, Universidade Estadual de Ponta Grossa, Ponta Grossa, 2008. 
SANTOS, Ligia Maria Rodrigues dos Santos. Transformação e valorização do espaço urbano do bairro Nova Rússia em Ponta Grossa - Paraná. Dissertação (Mestrado em Geografia). Curitiba, 2002, 131 f. Programa de pós-graduação em Geografia, Setor de Ciências da Terra, Universidade Federal do Paraná, Curitiba, 2002.

SANTOS, Milton. A natureza do espaço: Técnica e Tempo, Razão e Emoção. 4⿳亠丷 ed. São Paulo: Editora da Universidade de São Paulo, 2006.

O Espaço Geográfico como Categoria Filosófica. Terra Livre / O Espaço em Questão, n. 5, 1988.

PEREIRA, Gilberto Corso. Hipermidia e Visualização de Informações Urbanas. Anais do IV Congresso Ibero Americano de Gráfica Digital - SIGraDi'2000, 2000.

PEREIRA, Gilberto Corso; SILVA, B. C. N. Geoprocessamento e Urbanismo. In: Lucia Helena de Oliveira Gerardi; landara Alves Mendes. (Org.). Teoria, Técnicas, Espaços e Atividades: temas de Geografia contemporânea. 1 ed. Rio Claro: Programa de PósGraduação em Geografia - UNESP; AGETEO, p. 97-137, 2001.

PREFEITURA MUNICIPAL DE PONTA GROSSA/GEO PORTAL PONTA GROSSA. Geoportal Ponta Grossa - Arquivos em Formato SHP. Disponível em: <http://geo.pontagrossa.pr.gov.br/portal/arquivos_shp>. Acesso em: 15 dez. 2015.

TUAN, Yi-Fu. Espaço e lugar - a perspectiva da experiência. Londrina, PR: EDUEL, 2013. 